\title{
Editorial
}

\section{Inflamm-Aging: Arginase-II as Stage Setter in Age-Related Adipose Tissue Inflammation}

\author{
Stephan von Gunten \\ Institute of Pharmacology, University of Bern, Bern, Switzerland
}

Arginase-II (Arg-II) is a mitochondrial enzyme expressed in many extrahepatic tissues and hematopoietic cells that is involved in the hydrolysis of L-arginine to urea and L-ornithine. Arg-II is thought to promote cell growth and protein biosynthesis in health and cancer by the generation of L-ornithine as a precursor for the biosynthesis of polyamines $[1,2]$, and to downregulate immune responses by the reduced availability of L-arginine $[3,4]$. Interestingly, recent evidence suggests that Arg-II might enhance tumor metastasis by a mitochondrial pathway that is independent of L-arginine ureohydrolase activity, but may involve hydrogen peroxide production and STAT3 signaling [2], eventually as a result of p66Shc activation [5]. Given its multiple functions and broad expression, Arg-II is thought to be involved in many physiological and disease processes that still remain to be elucidated.

In this issue of Pharmacology, Huang et al. [6] report a role of Arg-II in age-associated adipose tissue inflammation by promoting IL- 6 production. IL- 6 is a key cytokine associated with inflamm-aging, and systemic IL-6 neutralization by a blocking antibody improves physical fitness in mice [7]. Huang et al. [6] showed that IL-6 mRNA and protein levels were increased in adipose tissue or in conditioned medium from peri-uterus fat tissue from old but not young mice. In contrast, both IL-6 mRNA and

karger@karger.com

(c) 2020 S. Karger AG, Basel

www.karger.com/pha

Karger! protein levels were significantly decreased in old Arg-II knockout (Arg- $-\mathrm{II}^{-/-}$) mice compared to age-matched wild-type mice, and less macrophage accumulation was observed. Pharmacological inhibition experiments revealed that in adipose tissue of old mice, the production of IL- 6 depends on p38 MAPK, of which total levels were reduced in old Arg- $\mathrm{II}^{-/-}$mice. Interestingly, L-arginine ureohydrolase activity in adipose tissue lysates was found to be higher in old Arg- $\mathrm{II}^{-/-}$mice, which was accountable to an overexpression of the cytoplasmic isoform Arg-I in the absence of Arg-II.

The study by Huang et al. [6] suggests that Arg-II is critically involved in age-related adipose tissue inflammation as it influences the production of a key cytokine (IL-6) in the process of inflamm-aging. Therapeutic strategies targeting immune cells and immune networks in aging adipose tissue may have great future potential. This is highlighted by a recent animal study showing that the transfer and adipose tissue homing of young donor eosinophils result in host rejuvenation with decreased local and systemic inflammation and increased physical and immune fitness [7]. Insights into age-related disease processes, including inflamm-aging, may provide a foundation for considerations in future personalized medicine approaches and clinical trial designs $[8,9]$. 


\section{Conflict of Interest Statement}

The author declares no conflicts of interest.

\section{Funding Sources}

The author did not recieve any funding.

\section{References}

1 Kusano T, Berberich T, Tateda C, Takahashi Y. Polyamines: essential factors for growth and survival. Planta. 2008;228(3):367-81.

2 Yu Y, Ladeiras D, Xiong Y, Boligan KF, Liang $\mathrm{X}$, von Gunten S, et al. Arginase-II promotes melanoma migration and adhesion through enhancing hydrogen peroxide production and STAT3 signaling. J Cell Physiol. 2020.

3 Munder M, Schneider H, Luckner C, Giese T, Langhans CD, Fuentes JM, et al. Suppression of T-cell functions by human granulocyte arginase. Blood. 2006;108(5):1627-34.
4 Steggerda SM, Bennett MK, Chen J, Emberley $\mathrm{E}$, Huang T, Janes JR, et al. Inhibition of arginase by CB-1158 blocks myeloid cell-mediated immune suppression in the tumor microenvironment. J Immunother Cancer. 2017 Dec 19;5(1):101.

5 Xiong Y, Yu Y, Montani JP, Yang Z, Ming XF. Arginase-II induces vascular smooth muscle cell senescence and apoptosis through p66Shc and p53 independently of its l-arginine ureahydrolase activity: implications for atherosclerotic plaque vulnerability. J Am Heart Assoc. 2013;2(4):e000096.

6 Huang J, Liu C, Ming X-F, Yng Z. Inhibition of $\mathrm{p} 38 \mathrm{mapk}$ reduces adipose tissue inflammation in aging mediated by arginase-II. Pharmacology. 2020 May 26.
7 Brigger D, Riether C, van Brummelen $\mathrm{R}$, Mosher KI, Shiu A, Ding Z, et al. Eosinophils regulate adipose tissue inflammation and sustain physical and immunological fitness in old age. Nat Metab. 2020 Jul 6.

8 von Gunten S. The future of pharmacology: towards more personalized pharmacotherapy and reverse translational research. Pharmacology. 2020;105(1-2):1-2.

9 Sun A, Benet LZ. Late-stage failures of monoclonal antibody drugs: a retrospective case study analysis. Pharmacology. 2020;105(3-4): 145-63. 